\title{
Delay in Seeking Medical Advice and Late Presentation of Female Breast Cancer Patients in Most of the World. Could We Make Changes? The Experience of 23 Years in Port Said, Egypt
}

\author{
Ahmed M. Elzawawya,b, c, d Alaadeen M. Elbahaie ${ }^{a, b, c} \quad$ Salah M. Dawood \\ Hussaam M. Elbahaie ${ }^{a}$ Atef Badran ${ }^{e}$ \\ a Faculty of Medicine, Suez Canal University, Ismailia, \\ ${ }^{b}$ Alsoliman Radiation Oncology Unit, \\ c Early Detection and Cancer Chemotherapy Unit, Port Said General Hospital, \\ ${ }^{d}$ Insurance Hospital, Port Said, \\ e $\mathrm{NCl}$, Cairo, Egypt
}

\section{Key Words}

Breast cancer - Delay · Cancer control · Treatment . Developing countries

\section{Summary}

Background: In the low and middle income countries delays in seeking consultation, late presentation, and the availability of breast cancer management for all patients, represent major challenges. Materials and Methods: The delay in seeking medical advice and the pathological tumor size of females breast cancer patients in the years 2004-2006 in Port Said, Egypt were studied and compared with previous studies by Elzawawy published since 1987 . We report the progress of availability of breast cancer management from 1984 until the end of June 2007. Results: There was a decline in advanced cases. Mean time from a symptom to seeking advice was $18,8,3$, and 1 month respectively in 1987, 1989, 1999, and 2007. Since 1984, facilities for all lines of comprehensive management have been established, interconnected, and been made accessible for all citizens, free of charge. Conclusion: Breast cancer problems are characterized by a certain multi-complexity. There is no one single cause for late cases. However, we report that the availability of cancer management facilities could lead to earlier presentation. Early detection programs would be frustrating for both patients and health authorities if patients were unable to afford accessible treatment.

\section{Schlüsselwörter}

Brustkrebs · Verspätung · Krebskontrolle · Behandlung · Entwicklungsländer

\section{Zusammenfassung}

Hintergrund: In Ländern niedrigen und mittleren Einkommens stellen die verspätete Suche nach medizinischem Rat, spätes Vorstelligwerden sowie die Verfügbarkeit von Brustkrebsmanagement für alle Patienten große Herausforderungen dar. Material und Methoden: Die verspätete Suche nach medizinischem Rat und die pathologische Tumorgröße bei Brustkrebspatientinnen im Zeitraum 2004-2006 in Port Said, Ägypten wurden untersucht und mit früheren Studien von Elzawawy (seit 1987) verglichen. Wir berichten über Fortschritte in der Verfügbarkeit von Brustkrebsmanagement von 1984 bis Ende Juni 2007. Ergebnisse: Wir konnten einen Rückgang in der Anzahl fortgeschrittener Stadien feststellen. Die Durchschnittszeit vom Auftreten eines Symptoms bis zur medizinischen Ratsuche betrug 18, 8, 3 bzw. 1 Monat in 1987, 1989, 1999 bzw. 2007. Seit 1984 sind Einrichtungen für alle Bereiche des umfassenden Krebsmanagements errichtet, miteinander verbunden und allen Einwohnern kostenfrei zugänglich gemacht worden. Schlussfolgerung: Brustkrebsprobleme sind durch ihre Multikomplexität gekennzeichnet. Für späte Präsentation gibt es mehr als nur eine Ursache. Dennoch konnten wir feststellen, dass die Verfügbarkeit von Krebsmanagementeinrichtungen zu früherem Vorstelligwerden führt. Früherkennungsprogramme wären für sowohl Patienten als auch Gesundheitsbehörden frustrierend, wenn Patienten vorhandene Behandlungsmöglichkeiten aus finanziellen Gründen nicht nutzen könnten.

\begin{tabular}{ll}
\hline KARGER & $\oplus$ 2008 S. Karger GmbH, Freiburg \\
Fax +49 761 45207 14 & Accessible online at: \\
$\begin{array}{l}\text { E-mail Information@Karger.de } \\
\text { www.karger.com }\end{array}$ & www.karger.com/brc
\end{tabular}

Prof. Dr. Ahmed Elzawawy, MD 


\section{Introduction}

The population and amount of cancer patients in the low and middle income countries (LMCs) are the highest worldwide. Breast cancer is the most frequent malignancy found among women in the world [1]. In Egypt, according to the Gharbiah population-based cancer registry, the relative frequency of breast cancer is around $37.6 \%$ of all malignancies among females [2]. According to El-Bolkainy [3], in a series of NCI, Cairo, Egypt, late presentation was a characteristic feature with most patients, and clinical T1, T2, T3, and T4 lesions were $1.2,30,26.4$, and $42.4 \%$, respectively [3]. Randomized trials of mammographic screening have provided strong evidence that early diagnosis as well as early start of management of breast cancer can reduce the specific mortality rate [4]. Moreover, in a recent systematic review of published studies, delays of 3-6 months between symptom onset and treatment have been found to be clearly associated with lower survival rates for breast cancer patients [5]. The availability of breast cancer management, which includes radiotherapy, for all patients represents a challenge in LMCs. The current study was conducted in Port Said which is located in the north-eastern part of Egypt with a population of 512,000 (in 2002) and an annual increase of $1.7 \%$. The male/female ratio is $1.02: 1$. In this mostly urban governorate, the first author, Dr. Ahmed Elzawawy has led and coordinated the progress of the availability of breast cancer treatment facility, free of charge for all citizens, through mobilization of local resources and interconnection of different health sectors. Before the year 1983, there were only facilities for surgery. From that time until 1994, free of charge facilities for diagnosis and chemotherapy, then also radiotherapy and all lines of comprehensive management and follow-up became established, interconnected, and accessible for all citizens. This experience attracted the onsite visits of different international experts. Accordingly, Elzawawy has participated in the summit meeting of the Breast Health Global Initiative (BHGI) 1-4 October 2007, Budapest, Hungary as a panelist and to present his experience in Port Said as an example of feasible implementation.

The aim of this work is to study the progress of availability of breast cancer treatment facilities between 26 February 1984 and the end of June 2007, and to examine in parallel the changes in delay in seeking medical advice, to measure the present time to start the management in the last series of 2004-2006, and the changes in tumor presentation in different successive series along 23 years in Port Said, Egypt.

\section{Patients and Methods}

The progress of availability, affordability, and accessibility of free of charge breast cancer management facilities for all citizens in Port Said is reported for the period of 1984 to June 2007. Concurrently, we conducted a cross-sectional study among 365 breast cancer female patients who presented with lumps in their breasts in the years 2004 to 2006 to Port Said oncology services that are connected to all health facilities and sectors in the whole city. These oncology units are namely the Alsoliman Hospital Radiation Oncology Department, the Port Said General Hospital Early Detection and Chemotherapy Unit, and The Port Said Insurance Hospital. This study is compared to our previous studies carried out since 1987. The lagtime - time from initial onset of symptom to the time of seeking medical advice [6] - and the delay - the lapse of more than 3 months between the appearance of cancer symptoms and medical consultation [7]were studied by interviewing patients at least 4 times within 6 months of diagnosis. The findings were compared to previous studies [8-11]. The time between the first consultation and the start of management is also examined in the current study, as well as the percentage of conservative treatment. Regarding the time trend in presentation from 1984 until the end of 2006, we chose the tumor size (T) among our detailed information as the breast lump is worldwide the main presentation. In order to have sure documented measures, we reported the histopathological $\mathrm{T}$ according to AJCC/UICC TNM. The pathological T in the recent series carried out in Port Said during the years 2004, 2005, and 2006 was compared to the previous series of 1984-1985 and 1994-1999. The total number of patients in the period of 2004-2006 was 349. The age varied between 19 and 84 years. $35.7 \%$ of the 349 patients were in age group $50-59$, and $27.1 \%$ were in age group 40-49. The peak incidence rate was observed in age group 50-54.

\section{Results}

The development of cancer services in Port Said since 1984 was as follows. In the second half of 1983 we started with facilities for breast surgery, X-ray, and only 1 private sonar. On 26 February 1984, the inauguration took place of the Early Detection and Chemotherapy Unit of Port Said General Hospital (founded in 1894). Since its establishment by Elzawawy in a disused part of the hospital, the services offered by this first ever chemotherapy unit have been free of charge. The cost of the transformation was $\$ 200$ only. As a referral unit, it is connected to all health services in Port Said. Drugs are covered from the general drugs expenses for hospitals. At present, the cost of 6 cycles of CMF (cyclophosphamide, methothreate, 5fluorouracil) is $\$ 39$, and $\$ 202$ for 6 cycles of FAC (5-fluorouracil, doxorubicin, cycolophosphamide). No overhead or other major expenses are incurred. No extra or special government funding was offered like that afforded for other cancer units in Egypt. Among the new 313 chemotherapy patients of the year 2006, this unit covered chemotherapy for $54.3 \%$ of patients, the insurance hospital covered $41.1 \%$, and $4.6 \%$ of patients were covered by their employers companies.

22 July 1994 was the date of the 1st session of radiotherapy that was performed by linear accelerator in the Alsoliman Hospital. Radiotherapy is free of charge for all patients in Port Said. A charity founded by one Egyptian family - the society of Alsoliman - covers all expenses of radiation oncology for all of Port Said, as well as of all cancer surgery for non-insured patients.

By 2007, in addition to the first unit, 5 pathology labs, a hospital and clinical registries, 2 mammography units, several X-ray machines, 2 computed tomography (CT) scanners and 1 mag- 


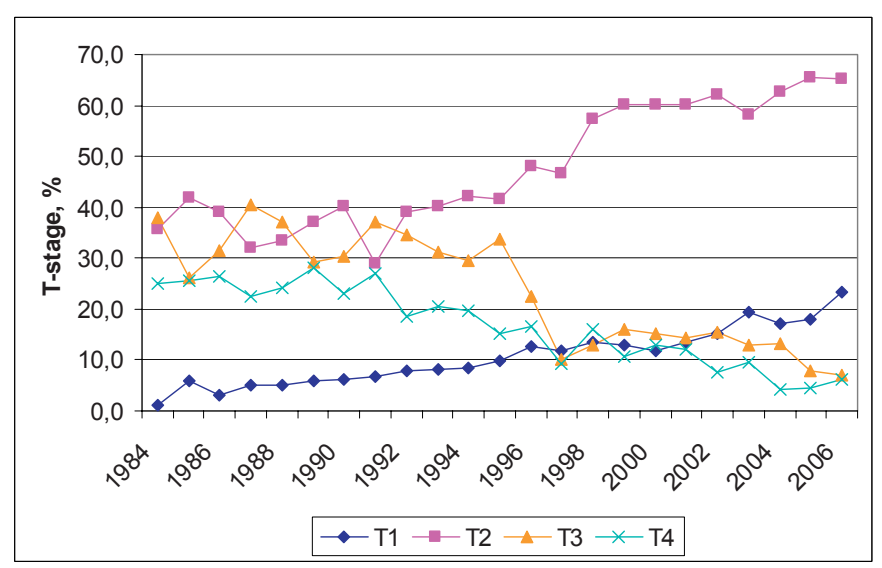

Fig. 1. Breast cancer in Port Said, Egypt according to T-stage, 1984-2006.

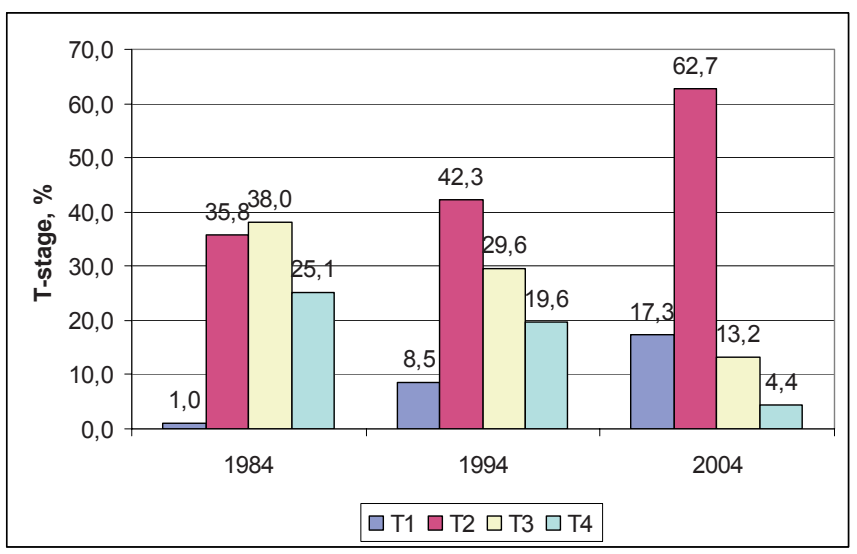

Fig. 2. Changes in percentage of T1-2-3-4 of primary diagnosis in breast cancer patitents in Port Said, Egypt.

netic resonance imaging (MRI) scanner, 11 ultrasonography units, laboratories, conservative breast cancer surgery facilities (around $20 \%$ of patients in the last 5 years had conservative surgery), chemotherapy (with taxanes, growth factors, aromatase inhibitors for selected cases), radiotherapy, palliative medical care and analgesics, nursing care, follow-up, social workers and support were established.

\section{Tumor Pathological Size}

As shown in figures 1 and 2, the distribution of T-stage has changed in the past 25 years. In $19841.0 \%$ of patients were T1, $35.8 \%$ were $\mathrm{T} 2,38.0 \%$ were $\mathrm{T} 3$, and $25.1 \%$ were T4. In 1994 , $8.5 \%$ of patients were $\mathrm{T} 1,42.3 \%$ were $\mathrm{T} 2,29.6 \%$ were $\mathrm{T} 3$, and $19.6 \%$ were $\mathrm{T} 4$.

In 2004 , of the total number of 99 cases, 50 patients $(50.5 \%)$ had tumors measuring $0-3 \mathrm{~cm}$. The number of conservative treatment was 11 cases $(11.1 \%)$. The tumor size distribution was as follows: T1: 17 (17.3\%), T2: 62 (62.7 \%), T3: 13 (13.2\%), T4: $4(4.4 \%) .2$ cases ( $2 \%)$ were inflammatory. Among the T2 cases, $33(33.3 \%)$ were $<2-3 \mathrm{~cm}$, and 29 (29.3\%) were $<3-5 \mathrm{~cm}$.
In 2005 , of the total number of 138 cases, 96 cases $(69.6 \%)$ were $0-3 \mathrm{~cm}$. Conservative treatment was carried out in 32 cases $(23.2 \%)$. The tumor size distribution was as follows: T1: 25 (18.1\%), T2: 96 (69.5\%), T3: 11(8\%), T4: 6 (4.4\%). 3 (2.3\%) cases were inflammatory. Among the T2 cases, 71 (51.4\%) were $<2-3 \mathrm{~cm}$, and $25(18.1 \%)$ were $<3-5 \mathrm{~cm}$.

In 2006 , of the total number of 112 cases, 75 cases $(67.0 \%)$ were $0-3 \mathrm{~cm}$. Conservative treatment took place in 23 cases (20.5\%). The tumor size distribution was as follows: T1: 26 (23.2\%), T2: 73 (65.2\%), T3: 8 (7.1\%), T4: 7 (6.25\%). 2 cases (1.8\%) were inflammatory. Among the T2 cases, 49 (43.75\%) were $<2-3 \mathrm{~cm}$, and $24(21.4 \%)$ were $<3-5 \mathrm{~cm}$.

\section{Delay in Seeking Medical Advice by Breast Cancer Patients Presenting with Breast Lumps}

The main points found by the 4 studies carried out in Port Said (1987, 1989, 1999, and the present study) were as follow:

In 1987, the mean lagtime was 18 months (1 week to 5 years). $76 \%$ of 50 patients asked advice after 3 months. In 1989, the mean lagtime was 8 months (few hours to 5 years). $68.7 \%$ of 80 patients sought advice after 3 months. In 1999, the mean lagtime was 3 months (few hours to 5.3 years). $43.8 \%$ of 182 patients sought advice after 3 months. In 2007, the mean lagtime was 1 month (few hours to 6 years; the latter was the case of an 82-year-old patient). $23 \%$ of 365 patients sought advice after 3 months.

Moreover, $92 \%$ realized the significance of the presence of a breast lump. Variations of fear - and not ignorance - are the main causes of delay. Fear of the socioeconomic consequences of the diagnosis of cancer, and fears of pain and death were more prominent than fear of disfigurement and mastectomy. Patients of more than 70 years of age had a more fatalistic outlook.

What made patients seek medical advice earlier were their hopes in treatment, and that cancer management is available to them, all are equal, and all have access to free of charge treatment, without traveling, and without significant financial and social disturbance of their life. This is what Elzawawy called 'keeping the socio-economic dignity of the patients and their families'. In the present study, $94 \%$ of patients had a mammography, fine-needle aspiration cytology, biopsy, or surgery within 2 weeks of seeking consultation.

\section{Discussion}

All that was presented here was achieved exclusively by local resources of the Port Said community, i.e. governmental, charity, insurance, private, and individual resources. All governmental, charity, insurance, private diagnostic, treatment, and care facilities have become interconnected.

The story of trials to develop cancer facilities in a region lacking most of them is a common one in developing countries. When Elzawawy returned from France in 1983, as many post- 
graduate doctors in developing counties who come back from Europe or the US, he had no oncology department and nor any comparable facilities. Before 1984, cancer patients who could travel went mostly to the very crowded Cairo with all the necessary expenses. Elzawawy's dream was to coordinate things in order to create access to all comprehensive cancer management free of charge for all citizens in Port Said where he was appointed. The 2 key words were: mobilization of local resources, and contribution of all possible players. 'I served as a human bridge and a focal point for connections with colleagues and younger staff. The present achievement is the result of the work of many colleagues in Port Said.' (Ahmed Elzawawy).

\section{Tumor Pathological Size (T)}

The results of the present study and the previous studies showed a decline of late $\mathrm{T}$ in accordance with the progression of facilities. In the last 2 years (2005 and 2006), the tumors of $3 \mathrm{~cm}$ and less were 72.7 and $59.8 \%$, respectively. Conservative breast cancer treatment was carried out for 23.3 and $20.5 \%$, respectively, which is remarkable bearing in mind that before 1984, conservative treatment was not possible in Port Said due to lack of facilities and late presentation.

\section{Delay in Seeking Medical Advice}

In the present study, the unique methodology that was introduced by Elzawawy in 1987 [12] was applied. This methodology indicated to interview each patient at least 4 times within 6 months. During the beginning of the first study in 1987, Elzawawy observed that lagtime and causes of delay differed enormously between the first interview and the last interview for the same patients, after gaining their trust and them realizing that we are offering all oncology management and care and not just a questionnaire. It was a chance for them to be relieved and to see that we understand each other $[11,12]$. Elzawawy stated 'I believe that - at least among Egyptians these types of what I call the one shot questionnaire and run! may lead to false and completely biased information! All studies without applying similar or equivalent methodology would be misleading if they didn't take in consideration such factors. Efforts, time and patience should be tried for deeply understanding of patients coming from different socio-economic and cultural background and various ways of expression of denial reflexes, even in the same community. I don't claim that what I did is ideal or complete, but it may be a step in the way'. As far as we know, the above-mentioned method of interviewing introduced by Elzawawy in 1987 is not mentioned in the literature.

It is noteworthy that Humphrey [13] drew the attention to the matter of reliability of reporting the delay as stated by patients in the first instance, and he concluded that the published figures must be regarded conservatively. The figures of the mean delay (3 months) was less than our previous studies. They were
$76,67.7,43.8$, and $23 \%$ in the studies of $1987,1989,1999$, and the present study, respectively. The figure of delay in the present study $(23 \%)$ is not far from the range of delay in some western studies, as it was one third of patients in the study of Facione and Dodd [14], and $19 \%$ of 185 patients in the study of Burgess [15].

The delay in seeking medical advice after the appearance of breast cancer symptoms is largely involved in advanced presentations and large tumor size at the time of diagnosis [16]. The factors involved in the delayed presentation of symptomatic breast cancer have been investigated by many authors in the developed countries [16-21], but few reported lack of resources and treatment facilities as a reason of delay in seeking advice. However, the problem of delay is much bigger in LMCs, and lack of resources and treatment facilities is the striking reason. Our findings can be summarized as follows: The more breast cancer treatment facilities are available free of charge and made accessible - with dignity - for all citizens, the less the delay in seeking medical advice, advanced presentations, and non-conservative surgery.

\section{Short Messages}

The level of our start could be found in many parts of underserved regions. Progress is possible and should be aimed at. Many could do better than we did. In our example the keys are: The will and patience of a clinical oncologist, to involve different active and potential players, mobilization of local resources and not running always for foreign help that after all is not enough, to start with what is available (you may start small but think big), to interconnect available facilities, to serve as a human bridge, to avoid long navigation of patients, to work quietly for years, to avoid wasting time on small things (unimportant things and dispute) present in all developing countries and attribute to the favor and the credit of many. Because it is true. We should be a part of the solution and not - without knowing - a part of the problem.

\section{Conclusion}

Beast cancer problems are multicomplex. Hence, there is no one single cause for the delay in seeking consultation. However, in the long term, the availability of cancer management facilities is associated with the reduction of delay and the increase of earlier diagnosis. Early detection programs would be frustrating for both patients and health authorities if patients were unable to afford reasonable treatment. Availability, affordability, and accessibly of breast cancer management facilities while respecting the socio-economic dignity of patients and their families and the propagation of this real information and experience via patients and their families are powerful calls for females in the community for early consultation for breast health and for follow-up. 


\section{Acknowledgment}

We thank all our colleagues in Port Said in different specialties. We are deeply grateful to the late Aly Soliman and the Society of Alsoliman, Port
Said, for the installation of the radiotherapy unit free of charge. Also, we thank Dr. Kasem Abdelhalim for his sincere contribution in radiation oncology. We are thankful to Prof. Nuran Bese, Istanbul, Turkey, for the helpful discussion during manuscript preparation.

\section{References}

1 Parkin DM, Bray F, et al.: Estimating the world cancer burden: Globocan 2000. Int J Cancer 2001;94: 153-6.

2 Ibrahim AS, Hussein H, et al.: Cancer Profile in Gharbiah-Egypt. Methodology and Results in 1999. GPCR, 2002

3 El-Bolkainy MN: Topographic Pathology of Cancer, 2nd ed. Cairo, National Cancer Institute. 2000.

4 Nyström L, Rutqvist LE, et al.: Breast cancer screening with mammography: overview of Swedish randomised trials. Lancet 1993;341:973-8.

5 Richards MA, Westcombe AM, et al.: Influence of delay on survival in patients with breast cancer: a systematic review. Lancet 1999:353:1119-26.

6 Worden JW, Weisman AD: Psychosocial components of lagtime in cancer diagnosis. J Psychosom Res 1975;19:69-79.

7 Harms RC, Plant JA, Oughterson AW: Delay in the treatment of cancer. JAMA 1943;121:335-9.

8 Elzawawy AM, Handy MH: Loco-regional contro of operable breast cancer. Early results of a protocol tailored for developing countries. Breast Diseases Senologia 1987;2:62-5.
9 Elzawawy AM: Delay in seeking medical advice by breast cancer patients presenting with a breast lump; in IAEA-TECDOC-614: Organization and Training in Radiotherapy for Developing Countries in Africa. IAEA, 1989, pp. 35-42.

10 Elzawawy AM, Hamdy MH: Management of operable breast cancer: realistic approach for developing countries. New Egypt J Med 1990;4:1955-7.

11 Elzawawy AM: Delay in seeking medical advice by breast cancer patients presenting with breast lump. Cancer Strategy 1999;1:16-9.

12 Elzawawy AM: Delay in seeking medical advice by breast cancer females patients. Egypt J Radiol Nuclear Med 1987;XVIII:85-9.

13 Humphrey M: Delay in seeking medical advice for breast symptoms; in Brand BC, van Keep PA (eds): Psycho-Social Aspects of Early Detection and Treatment. Lancaster, MTP Press, 1978, pp. 57-65.

14 Facione NC, Dodd MJ: Women's narratives of helpseeking for breast cancer. Cancer Pract 1995;3: 219-25.

15 Burgess CC, Ramirez AJ, et al.: Who and what influences delayed presentation in breast cancer? $\mathrm{Br}$ J Cancer 1998;77:1343-8.
16 Arndt V, Stürmer T, et al.: Patient delay and stage of diagnosis among breast cancer patients in Germany - a population based study. Br J Cancer 2002;86: 1034-40.

17 Adam SA, Horner JK, Vessey MP: Delay in treatment for breast cancer. Community Med 1980;2: 195-201.

18 Andersen BL, Cacioppo JT: Delay in seeking a cancer diagnosis: delay stages and psychophysiological comparison processes. Br J Soc Psychol 1995;34:3352 .

19 Burgess C, Hunter MS, Ramirez AJ: A qualitative study of delay among women reporting symptoms of breast cancer. Br J Gen Pract 2001;51:967-71.

20 De Nooijer J, Lechner L, de Vries H: A qualitative study on detecting cancer symptoms and seeking medical help; an application of Andersen's model of total patient delay. Patient Educ Couns 2001;42: $145-57$.

21 Montella M, Crispo A, et al.: An assessment of delays in obtaining definitive breast cancer treatment in Southern Italy. Breast Cancer Res Treat 2001;66: 209-15. 